\title{
Effect of increased yield strength, R-ratio, and plate thickness on the fatigue resistance of high-frequency mechanical impact (HFMI)-treated steel joints
}

\author{
M. Leitner ${ }^{1}$ (1) $\cdot$ Z. Barsoum ${ }^{2}$ \\ Received: 10 May 2019 / Accepted: 27 April 2020 / Published online: 13 May 2020 \\ (C) The Author(s) 2020
}

\begin{abstract}
In 2016, the International Institute of Welding (IIW) published a recommendation for high-frequency mechanical impact (HFMI) treatment for improving the fatigue strength of welded joints. Since the publication of the HFMI recommendations, numerous of studies have been published with a considerable amount of new fatigue test data focusing on various aspects of the improvement; influence of base material yield strength, and loading and thickness effects. Since the data was scarce covering some of the aspects when the recommendation was published, re-evaluating the recommendation with these new test data, presented within this work, will further validate and extend the recommendations. The analysis reveals that the recommended improvement of fatigue classes based on the base material yield strength is well applicable. In addition, the reduction of fatigue classes for higher $\mathrm{R}$-ratios up to the defined value of $\mathrm{R}=0.52$ is well considered. Finally, the practicability of the thickness correction factor is also confirmed by leading to a conservative fatigue assessment. The ratio of the statistically evaluated FAT class to the recommended value is shown to be conservative with a value of above one for almost every data set; however, even the ratio is below one in some minor cases, every single test data point in this study is assessed conservatively validating the applicability of the recommendation.
\end{abstract}

Keywords Fatigue strength $\cdot$ HFMI-treatment $\cdot$ Yield strength $\cdot$ R-ratio $\cdot$ Plate thickness

\section{Introduction}

Weld toe improvement methods have been widely investigated and have in most cases been found to give substantial increases in fatigue strength. However, there are large variations in the actual improvements achieved and clear dependency of the base material yield strength. According to the IIW recommendation [1], the fatigue strength of welded steel joints is generally independent of the base material's yield strength in the as-welded condition. However, when post-

Recommended for publication by Commission XIII - Fatigue of Welded Components and Structures

M. Leitner

martin.leitner@unileoben.ac.at

1 Department Product Engineering, Chair of Mechanical Engineering, Montanuniversität Leoben, Leoben, Austria

2 Department of Aeronautical and Vehicle Engineering, KTH Royal Institute of Technology, Stockholm, Sweden weld improvement techniques are used with the target of enhancing the fatigue strength, there is a clear observation of that an increase in yield strength of the base material will render an increase of the fatigue strength for some post-weld improvement techniques investigated. This has been addressed in the IIW recommendations on improvement techniques in 2013 [2] for selected methods such as burr grinding [3], TIG dressing [4], and hammer [5] and needle peening [6]. These improvement techniques could be divided into two different groups, mainly depending on the type of improvement: residual stress modification (hammer and needle peening) or geometrical modification (burr grinding and TIG dressing).

Haagensen and Maddox [2] recommend up to $30 \%$ enhancement of the fatigue strength for geometry modification techniques and up to $30 \%$ for $f_{\mathrm{y}}<355 \mathrm{MPa}$ and up to $50 \%$ for $f_{\mathrm{y}}>355 \mathrm{MPa}$, assuming a $\mathrm{S} / \mathrm{N}$ slope of $m=3$ for all welded joints. This fatigue strength improvement revealed to be too conservative for residual stress modification techniques, in particular for high-frequency mechanical impact (HFMI) treatment methods. Figure 1 provides an overview of different improvement techniques on the market today. Green is 

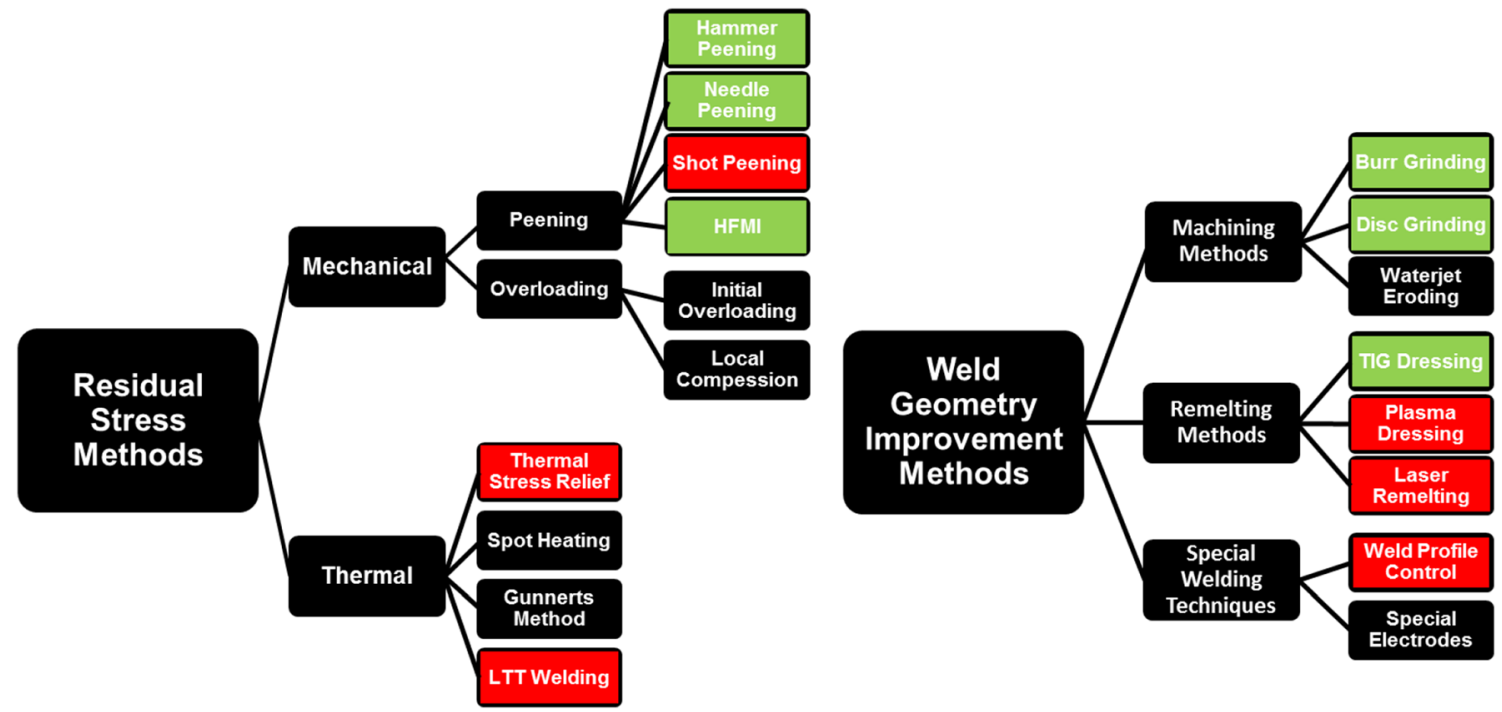

Fig. 1 Overview of different weld improvement techniques

covered by IIW recommendations [1, 2]; red is planned and/or in progress.

HFMI has emerged as a reliable, effective as well as userfriendly method for post-weld fatigue strength improvement technique for welded structures. It has been shown in numerous of studies [7-10] that the compressive residual stresses introduced by HFMI, due to impacted material is highly plastically deformed causing changes in the material microstructure and the local geometry, are in the range of the base material yield stress magnitude. It has also been demonstrated that the compressive residual stresses are stable during fatigue loading, with moderate relaxation $[11,12]$. The HFMI techniques have been demonstrated to be suitable to improve the fatigue strength of large/infra welded structures [13] and an alternative method for extending the life and rehabilitation of welded structures in service [14].

In 2016, IIW published [15] a recommendation for HFMI for improving the fatigue strength of welded joints. The recommendation presents a guideline on proper treatment

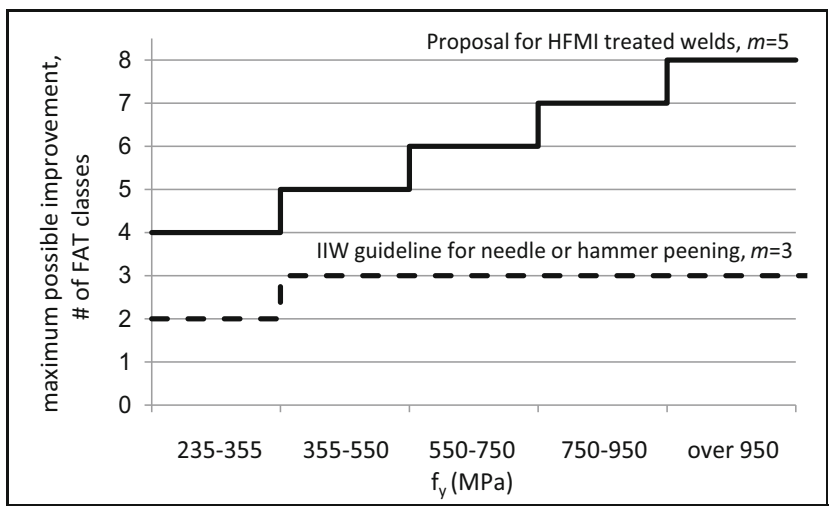

Fig. 2 "Staircase" improvement for HFMI-treated welds [15] procedures, quality control measures, and fatigue strength improvement assessment based on nominal, hot spot, and effective notch stress methods. It also includes detailed recommendation on the effect of base yield strength, loading conditions, thickness effects, variable amplitude loading, low cycle fatigue, and consideration of low-stress concentration. It is mainly based on fatigue test data presented in IIW Commission XIII documents during the period 2002-2012 reporting HFMI technology or experimental studies involving HFMI based fatigue strength improvement.

One of the key features of the HFMI recommendations [15] is the increase of the fatigue strength as function of the base material yield strength; approximately $12.5 \%$ increase in fatigue strength with an increase of $200 \mathrm{MPa}$ in yield strength assuming a $\mathrm{S} / \mathrm{N}$ slope of $m=5$ for all joints. The recommendation covers structural steels ranging from 235 to $>950$ in $f_{\mathrm{y}}(\mathrm{MPa})$. Figure 2 shows the "staircase" improvement in number of FAT classes as function of $f_{\mathrm{y}}$ for HFMI-treated welds [15] as well as for needle and hammer peened welds [2].

Table 1 Minimum reduction in the number of FAT classes in fatigue strength improvement for HFMI-treated welded joints based on R-ratio [15]

\begin{tabular}{ll}
\hline R-ratio & Minimum FAT class reduction \\
\hline $\mathrm{R} \leq 0.15$ & No reduction due to stress ratio \\
$0.15<\mathrm{R} \leq 0.28$ & One FAT class reduction \\
$0.28<\mathrm{R} \leq 0.4$ & Two FAT classes reduction \\
$0.4<\mathrm{R} \leq 0.52$ & Three FAT classes reduction \\
$0.52<\mathrm{R}$ & $\begin{array}{l}\text { No data available. The degree of } \\
\text { improvement must be confirmed by testing }\end{array}$ \\
\hline
\end{tabular}




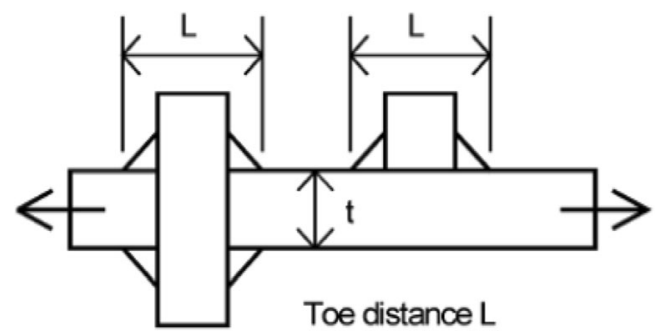

Fig. 3 Definition of $L$ used to determine the thickness correction factor [1]

The HFMI recommendation [15] also provides design guidelines for loading effects and R-ratio. For welded structures improved by HFMI, the techniques are not suitable for $\mathrm{R}>0.5$ or when $\sigma_{\max }>0.8 f_{\mathrm{y}}$. These restrictions are intended to influence the fatigue design assessment of structures when the beneficial compressive residual stress state due to post weld improvement may not be stable. HFMI-treated welds can have up to 8 FAT classes of improvement depending on the material strength and welded joint geometry. The stress ratio influence is expressed as a "penalty" with respect to the maximum increase in the number of FAT classes as a function of $f_{\mathrm{y}}$. These reduction factors are presented in Table 1.

The design proposal for HFMI is applied to plate thicknesses of $t_{\text {eff }}=5-50 \mathrm{~mm}$. Plate thickness and weld size influence the local stress concentration at the weld toe, and assessment with nominal (and hot-spot) stress method requires thickness reduction factor for plate thicknesses exceeding $t_{\text {eff }}=25 \mathrm{~mm}$. The reduction factor is presented in Hobbacher [1]. This thickness correction factor $f(t)$ for toe ground joints is given in Eq. (1):

$f(t)=\left(\frac{25}{t_{\text {eff }}}\right)^{0.2}$

where $t_{\text {eff }}=L / 2$ for $L / t<2$ and $t_{\text {eff }}=t$ for $L / t \geq 2$. As seen in Fig. 3, $L$ is the sum of the thickness or length of the attachment and the weld leg lengths.

Since the publication of the HFMI recommendations [15], numerous of studies have been published with a considerable amount of new fatigue test data focusing on various aspects of the improvement: base material yield strength effect, loading effect, and thickness effect. Since the data was scarce covering some of the aspects when the recommendation was published, re-evaluating the recommendation with these new test data, presented in Sect. 2, will further validate and extend the recommendations. More precisely, the current study aims to validate and extend recommendations of abovementioned effects based on new experimental data.
Table 2 Overview of fatigue test data sets

\begin{tabular}{|c|c|c|c|c|c|c|}
\hline Data set & Reference & Specimen type & $\begin{array}{l}\text { Yield strength } \\
{[\mathrm{MPa}]}\end{array}$ & Thickness [mm] & R-ratio [-] & Load type \\
\hline$\# 1$ & [19] & Butt joint & 1100 & 6 & 0.1 & Tensile \\
\hline$\# 2$ & {$[20]$} & Butt joint & 1100 & 6 & 0.1 & Tensile \\
\hline$\# 3$ & {$[21]$} & Overlap joint & 1100 & 6 & 0.1 & Tensile \\
\hline$\# 4$ & {$[21]$} & Overlap joint & 1300 & 4 & 0.1 & Tensile \\
\hline$\# 5$ & {$[21]$} & T-joint & 1100 & 6 & 0.1 & Tensile \\
\hline \#6 & {$[21]$} & T-joint & 1300 & 4 & 0.1 & Tensile \\
\hline$\# 7$ & {$[21]$} & Long. stiffener & 1100 & 6 & 0.1 & Tensile \\
\hline$\# 8$ & {$[21]$} & Long. stiffener & 1300 & 4 & 0.1 & Tensile \\
\hline$\# 9$ & {$[22]$} & Long. stiffener & 575 & 12 & $0.00-0.15$ & Tensile \\
\hline$\# 10$ & {$[22]$} & Long. stiffener & 575 & 12 & $0.16-0.34$ & Tensile \\
\hline$\# 11$ & {$[22]$} & Long. stiffener & 575 & 12 & $0.35-0.50$ & Tensile \\
\hline$\# 12$ & {$[22]$} & Long. stiffener & 575 & 12 & $0.51-0.60$ & Tensile \\
\hline$\# 13$ & {$[22]$} & Long. stiffener & 575 & 12 & $>0.60$ & Tensile \\
\hline$\# 14$ & {$[23]$} & Butt joint & 355 & 30 & 0.1 & Tensile \\
\hline$\# 15$ & {$[23]$} & Butt joint & 460 & 30 & 0.1 & Tensile \\
\hline$\# 16$ & {$[23]$} & Butt joint & 690 & 30 & 0.1 & Tensile \\
\hline \#17 & {$[23]$} & Long. stiffener & 355 & 30 & 0.1 & Tensile \\
\hline$\# 18$ & {$[23]$} & Long. stiffener & 690 & 30 & 0.1 & Tensile \\
\hline \#19 & {$[23]$} & T-joint & 460 & 30 & 0.1 & Tensile \\
\hline \#20 & {$[24]$} & T-joint & 355 & 40 & $0.00-0.16$ & Bending \\
\hline \#21 & {$[24]$} & T-joint & 355 & 60 & $0.00-0.16$ & Bending \\
\hline \#22 & {$[24]$} & T-joint & 460 & 40 & $0.00-0.16$ & Bending \\
\hline$\# 23$ & {$[24]$} & T-joint & 460 & 60 & $0.00-0.16$ & Bending \\
\hline
\end{tabular}




\section{Results}

\subsection{Overview of test series}

In [16], a comprehensive overview of fatigue data for HFMItreated steel joints is provided covering the effect of HFMI on the fatigue strength for base material yield strength's up to $960 \mathrm{MPa}$ at a load stress ratio of mostly $\mathrm{R}=0.1$ under constant amplitude loading (CAL). Furthermore, the influence of higher R-ratios as well as variable amplitude loading (VAL) is researched [17], and the effect of overloads in [18] for HFMI-treated jointssummarizing that the recommendation is generally well applicable. This paper enhances the preceding studies in regard to the applicability of the HFMI guideline for increased steel joints with an increased yield strength of $f_{\mathrm{y}} \geq 1100 \mathrm{MPa}$ as well as for higher load stress ratios up to $\mathrm{R}>0.6$ and plate thicknesses with $t_{\text {eff }}>25 \mathrm{~mm}$. A summary of the investigated published fatigue test data within this paper is provided in Table 2.

In the subsequent Figs. 4, 5, 6, 7, 8, 9, 10, 11, 12, 13, 14, $15,16,17,18,19,20,21,22$, and 23 within Sects. 2.2 to 2.4, the fatigue test data points of the data sets as well as their statistically evaluated $\mathrm{S} / \mathrm{N}$ curve, applying the standard procedure given in [25], for a survival probability of $P_{S}=97.5 \%$ in accordance with $[1,15]$, are shown. The $\mathrm{S} / \mathrm{N}$ curves are presented within the range of the tested load cycles of each data set, which act as basis for the statistical evaluation. Furthermore, the statistically evaluated FAT class, the slope $m$ as well as the scatter band $1: \mathrm{T}_{\mathrm{S}}$, which is defined as the ratio of the fatigue strength at $\mathrm{P}_{\mathrm{S}}=10 \%$ to $\mathrm{P}_{\mathrm{S}}=90 \%$ according to [26], is stated at the caption of each figure. A summary of the results showing a quantitative comparison of the statistically evaluated and recommended FAT values for each data set is presented in Sect. 2.5.

\subsection{Effect of increased yield strength}

At first, the effect of increased base material yield strengths with $f_{\mathrm{y}} \geq 1100 \mathrm{MPa}$ is analyzed. In Fig. 4, the results for data set \#1 including a high-strength S1100 butt joint with a plate of thickness of $t=6 \mathrm{~mm}$ tested under tensile loading at a load stress ratio of $\mathrm{R}=0.1$ are depicted. The as-welded (AW) FAT class exhibits a value of FAT 90 for this specimen type. Based on the HFMI guideline, an increase by eight FAT classes is given leading to FAT 180 for the HFMI-treated condition. A comparison with the fatigue test data points as well as their statistically evaluated $\mathrm{S} / \mathrm{N}$ curve reveals that the recommended $\mathrm{S} / \mathrm{N}$ curve based on the guideline is conservative and well applicable.

Figure 5 presents the results for data set \#2 incorporating again a high-strength $\mathrm{S} 1100$ butt joint with a plate of thickness of $t=6 \mathrm{~mm}$ tested under tensile loading at a load stress ratio of $\mathrm{R}=0.1$. Due to the different butt weld geometry, the FAT class of the AW condition is defined as FAT 71 in this case. For the fatigue assessment of the HFMI-treated state, the same improvement factors based on the HFMI guideline as shown in the previous data set are applied leading to FAT 180 for the HFMI-treated state. The results indicate that the fatigue test points of data set \#2 exhibit a minor fatigue strength compared with data set \#1. However, the fatigue assessment based on the HFMI guideline for the presented test data points and their statistically evaluated $\mathrm{S} / \mathrm{N}$ curve within the range of the load cycles of the test data is still conservative.

In Fig. 6, the results for the data sets \#3 and \#4 are demonstrated. Both fatigue test data points include an overlap joint tested under tensile loading at a load stress ratio of $\mathrm{R}=0.1$. Data set \#3 exhibits S1100 steel joints with a plate thickness of $t=6 \mathrm{~mm}$ and data set \#4 S1300 steel joints with a plate thickness of $t=4 \mathrm{~mm}$. The AW FAT class if defined as FAT 56 for this type of weld joint. Applying the recommended increase of eight FAT classes according to the HFMI guideline, a FAT
Fig. 4 Results for data set \#1 (S1100: FAT 309, $m=5.1,1: \mathrm{T}_{\mathrm{S}}=$ 1.14)

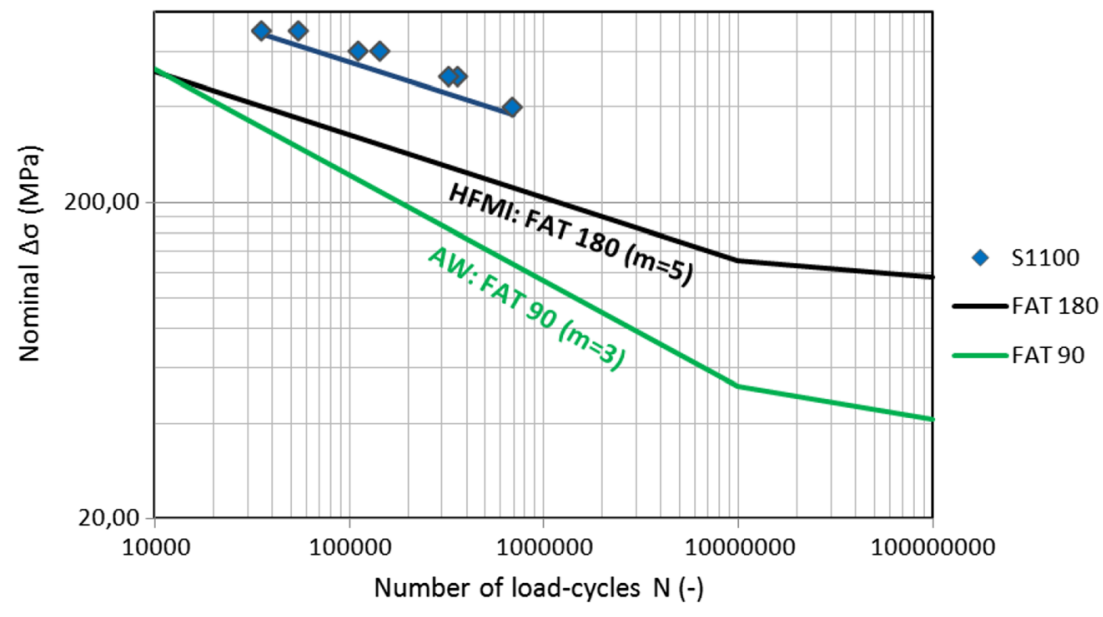


Fig. 5 Results for data set \#2

(S1100: FAT 170, $m=3.6,1: \mathrm{T}_{\mathrm{S}}=$ 1.53)

Fig. 6 Results for data set \#3 and \#4 (S1100/S1300: FAT 215/204, $\left.m=6.5 / 5.4,1: \mathrm{T}_{\mathrm{S}}=1.23 / 1.03\right)$

Fig. 7 Results for data set \#5 and \#6 (S1100/S1300: FAT 148/180, $m=3.0 / 5.0,1: \mathrm{T}_{\mathrm{S}}=1.17 / 1.18$
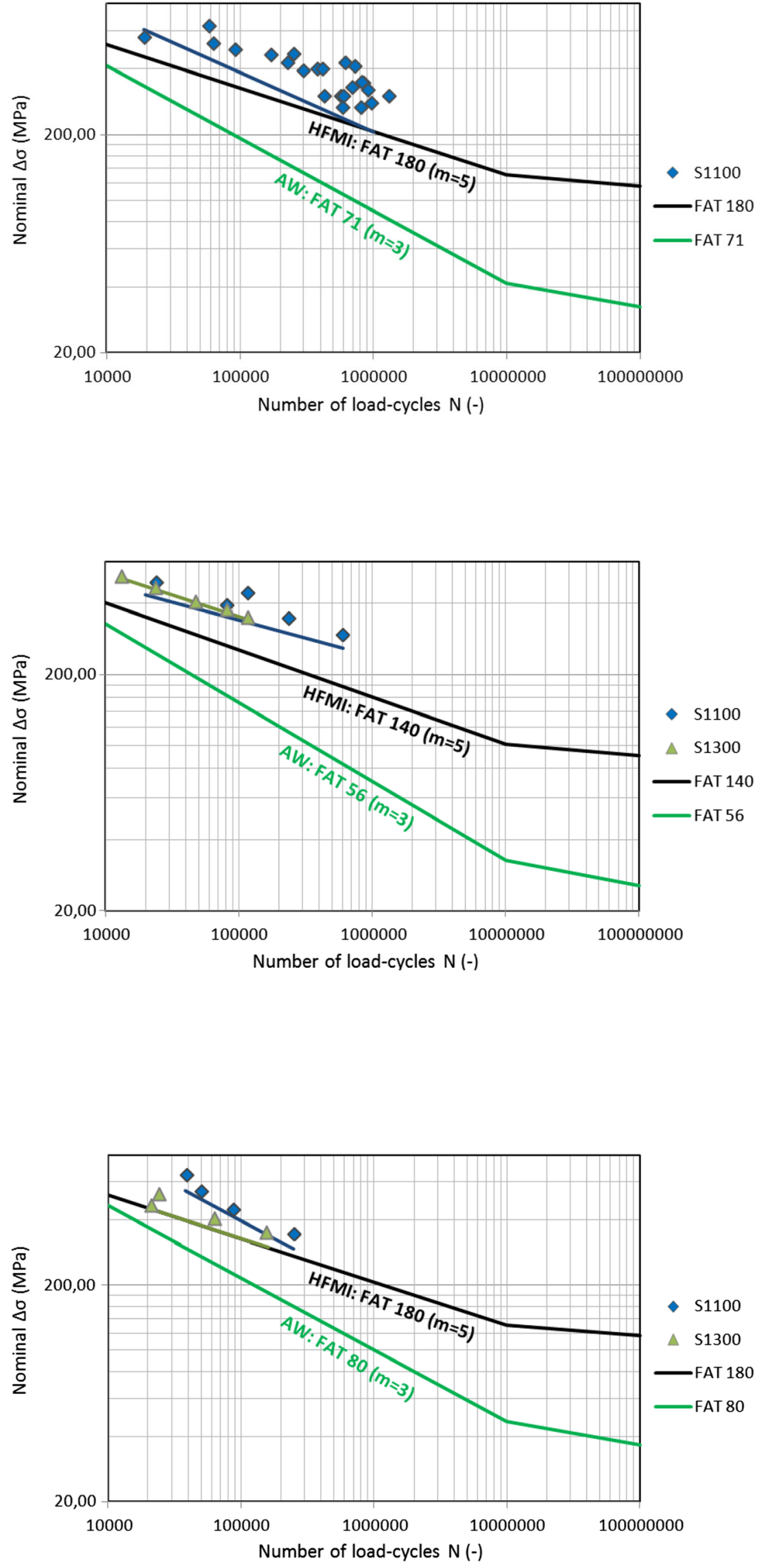
Fig. 8 Results for data set \#7 and \#8 (S1100/S1300: FAT 163/84, $\left.m=4.9 / 3.0,1: \mathrm{T}_{\mathrm{S}}=1.21 / 1.11\right)$

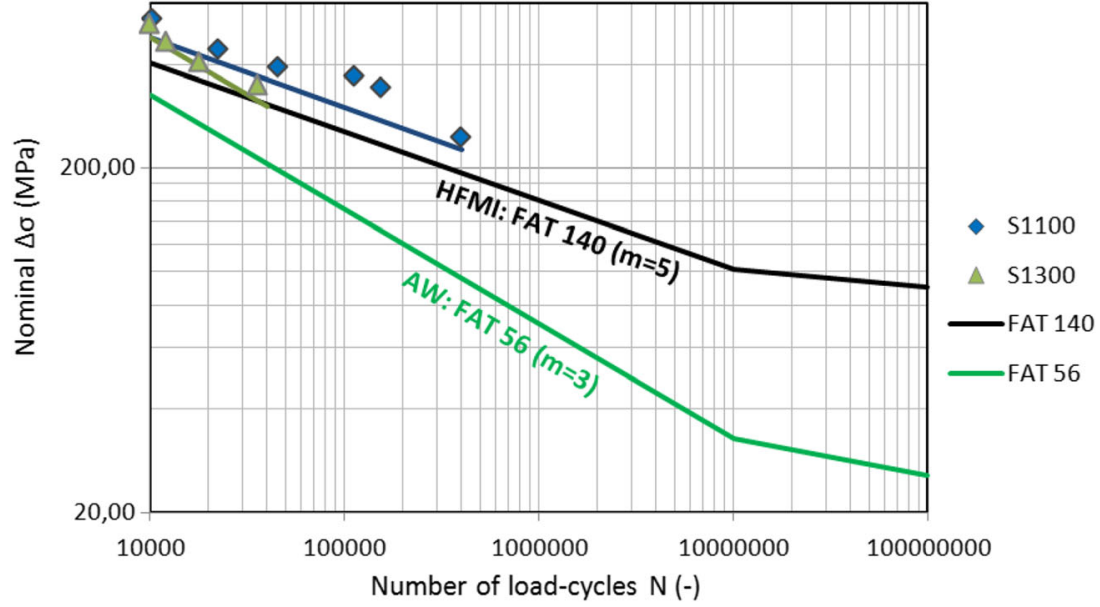

class of FAT 140 is evaluated for the HFMI-treated condition for both data sets. A comparison of the fatigue test data points of both S1100 and S1300 test series as well as their statistically evaluated $\mathrm{S} / \mathrm{N}$ curves with the recommended $\mathrm{S} / \mathrm{N}$ curve reveals a sound applicability with a conservative fatigue assessment.

The same base materials, plate thicknesses, and testing conditions are applied within data set \#5 and \#6 for a T-joint geometry. In this case, the FAT class for the AW state is defined as FAT 80. Considering an eight FAT class improvement as recommended by the HFMI guideline, the FAT class for both data sets is calculated to FAT 180. A comparison shows that the recommended $\mathrm{S} / \mathrm{N}$ curves are still well applicable; however, the test data points of the S1300 joints and their statistically evaluated $\mathrm{S} / \mathrm{N}$ curve are close to the assessment line, but still a conservative design is enabled.

Finally, again the same base materials, plate thicknesses, and testing conditions as before are applied within data set \#7 and \#8 for a longitudinal stiffener. Thereby, the FAT class of the AW condition is defined as FAT 56, which leads to FAT 140 according to the HFMI guideline. Comparing the fatigue test data points with the recommended $\mathrm{S} / \mathrm{N}$ curves a similar conclusion as for the preceding T-joint data sets can be drawn. A conservative assessment is enabled; however, the test data points and their statistically evaluated $\mathrm{S} / \mathrm{N}$ curve within the tested load cycles of the S1300 joints are again close to the assessment line.

Summarizing the results of this section, the recommended $\mathrm{S} / \mathrm{N}$ curves by the HFMI guideline [15] lead to a conservative assessment focusing on the presented fatigue test data points for increased base material yield strengths with $f_{\mathrm{y}} \geq 1100 \mathrm{MPa}$. In case of the data sets \#2, \#5, and \#8, a ratio of the statistically evaluated to the recommended FAT class below a value of one is given, which basically results from a steeper slope of the $\mathrm{S} /$ $\mathrm{N}$ curve below the recommended value of $m=5.0$ based on the guideline.

However, within the tested load cycles for each data set, both the test data points as well as the resulting $\mathrm{S} / \mathrm{N}$ curves are
Fig. 9 Results for data set \#9 (FAT $169, m=6.8,1: \mathrm{T}_{\mathrm{S}}=1.14$ )

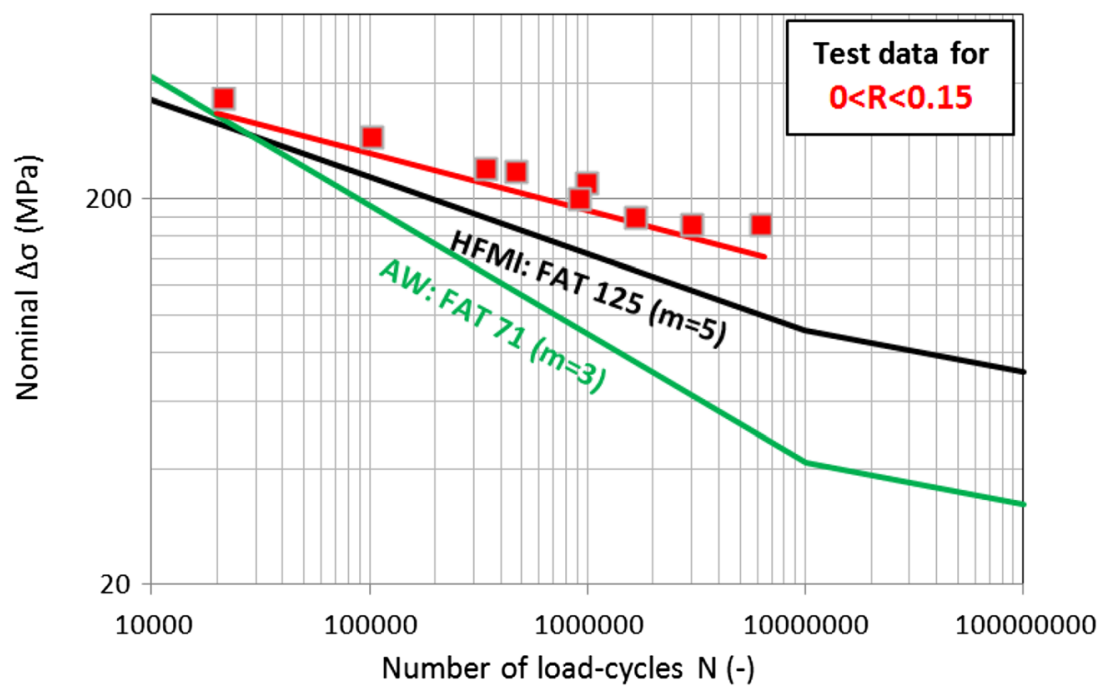


Fig. 10 Results for data set \#10 (FAT $122, m=5.7,1: \mathrm{T}_{\mathrm{S}}=1.18$ )

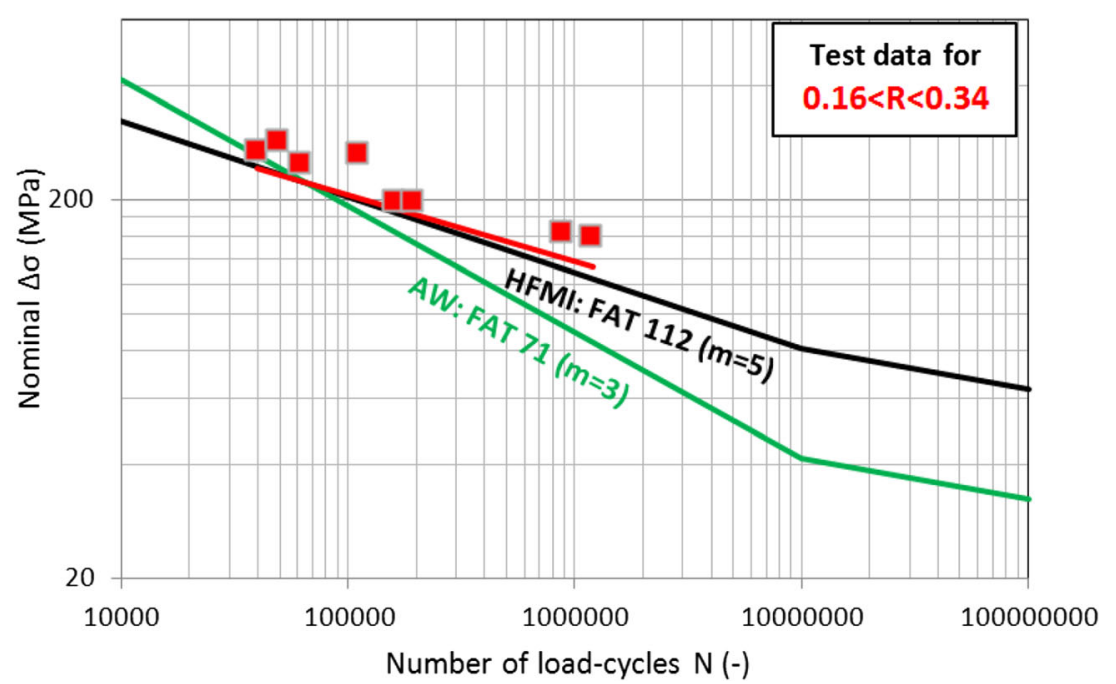

conservatively assessed, which validates the applicability of the HFMI-recommended values for increased yield strengths.

\subsection{Effect of increased R-ratio}

At second, the effect of increased load stress ratios with Rratios up to $\mathrm{R}>0.6$ is analyzed. In Fig. 9, the results for data set \#9 including a longitudinal stiffener with a yield strength of $575 \mathrm{MPa}$ and a plate thickness of $t=12 \mathrm{~mm}$ tested under tensile loading at a load stress ratio of $0<\mathrm{R}<0.15$ are depicted. The as-welded (AW) FAT class exhibits a value of FAT 71 for this specimen type. Based on the HFMI guideline, an increase by five FAT classes is evaluated leading to FAT 125 for the HFMI-treated condition. A comparison with the fatigue test data points as well as their statistically evaluated S/ $\mathrm{N}$ curve shows that the recommended $\mathrm{S} / \mathrm{N}$ curve is conservative and well applicable.

Figure 5 presents the results for data set \#10 incorporating the same base material and plate thickness within data set \#9, but tested under an increased load stress ratio of $0.16<\mathrm{R}<$
0.34. The HFMI guideline recommends a reduction of one fatigue class for $0.15<\mathrm{R} \leq 0.28$, which is applied within this evaluation and leads to a fatigue class of FAT 112. Although some of the data points are tested at a higher load stress ratio of $0.28<\mathrm{R}<0.34$, a comparison of the recommended $\mathrm{S} / \mathrm{N}$ curve with the fatigue test data points and their statistically evaluated $\mathrm{S} / \mathrm{N}$ curve shows that the HFMI guideline still leads to a proper assessment.

In Fig. 11, the results for the same specimens as presented before, but tested under a further increased load stress ratio of $0.35<\mathrm{R}<0.5$, are depicted. According to the HFMI guideline, a reduction of two fatigue classes should be considered for $0.28<\mathrm{R} \leq 0.4$, which equals FAT 100 in this case. Again, even though some data points are tested above $R=0.4$, the recommended fatigue behavior for the HFMI-treated condition is well applicable and still slightly conservative for all test data points and their statistically evaluated $\mathrm{S} / \mathrm{N}$ curve.

Figure 12 shows the results for the same specimens as before, but tested under a further increased load stress ratio of $0.51<\mathrm{R}<0.6$. Based on the HFMI guideline, three fatigue
Fig. 11 Results for data set \#11 (FAT 108, $m=5.4,1: \mathrm{T}_{\mathrm{S}}=1.15$ )

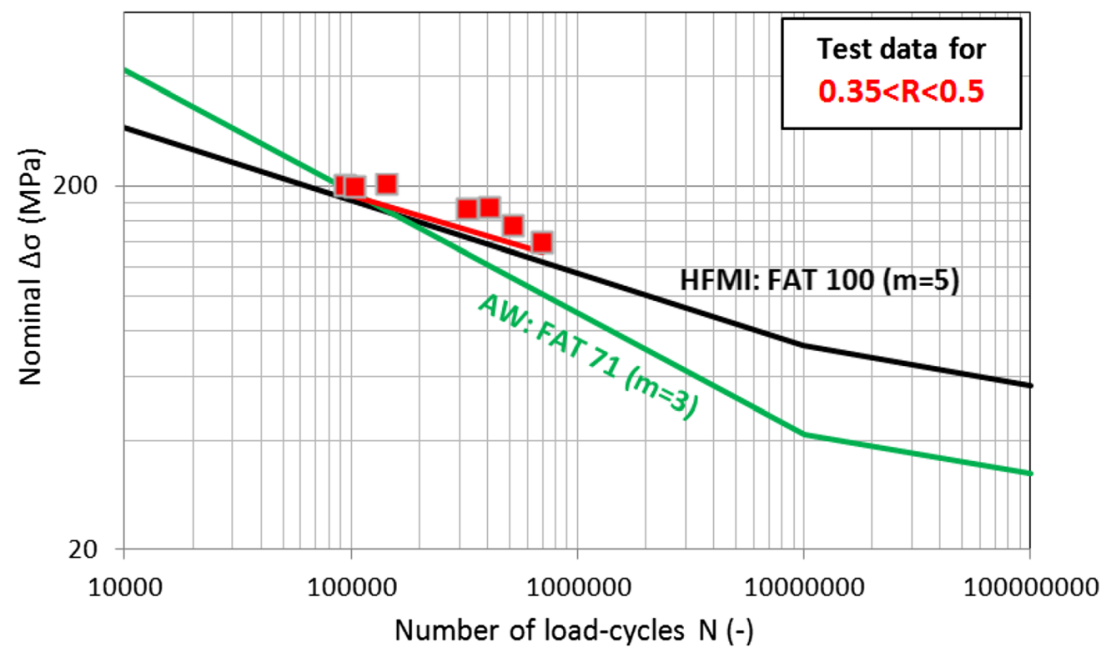


Fig. 12 Results for data set \#12

(FAT 92, $m=5.1,1: \mathrm{T}_{\mathrm{S}}=1.34$ )

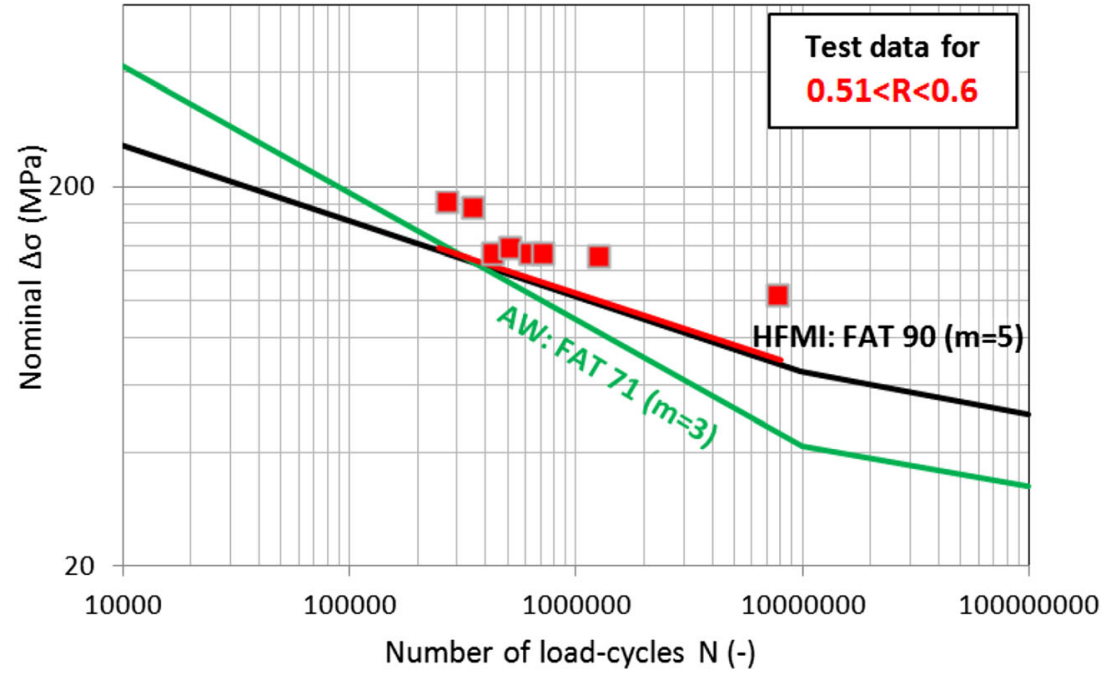

classes should be reduced for load stress ratios of $0.4<\mathrm{R} \leq$ 0.52 , which is applied for this data set and leads to a fatigue class of FAT 90. As in this case, most of the data points are tested a comparably higher R-ratio above 0.52 , a comparison with the test data points and their statistically evaluated $\mathrm{S} / \mathrm{N}$ curve reveals that the recommendation is still fine featuring a conservative fatigue assessment. Hence, the recommended reduction for increased R-ratios is observed to be well and conservatively applicable.

Finally, a maximum load stress ratio of $0.6<\mathrm{R}$ is applied for the same specimens as shown before. For such high Rratios, no recommendation within the HFMI guideline exists at the moment. However, continuing the procedure within the guideline, a reduction of four fatigue classes is applied leading to FAT 80 . A comparison of this assumed $\mathrm{S} / \mathrm{N}$ curve with the fatigue test data points in Fig. 13 indicates that the assessment may be again applicable, whereas no data point is nonconservatively located below this assessment line. However, the statistically evaluated $\mathrm{S} / \mathrm{N}$ curve shows to fit well to the recommended assessment line of the as-welded condition indicating no benefit by the HFMI-treatment for such high R-ratio values. Therefore, no general recommendation based on these results can be given, and further fatigue test data including experimental results of HFMI-treated joints tested a high R-ratio should be analyzed for validation.

Summarizing the results of this section, the recommended $\mathrm{S} / \mathrm{N}$ curves by the HFMI guideline are again well applicable for increased load stress ratios up to a value of about $R=0.5$. For higher $R$-ratios in the range of $0.5<\mathrm{R}$, further fatigue tests covering different specimen types and base material steel strengths should be performed. However, a comparison of the fatigue test data points and their statistically evaluated $\mathrm{S} / \mathrm{N}$ curves included in this study illustrates that the recommended decrease of the FAT class by an increased R-ratio up to a value of about $\mathrm{R}=0.5$ is basically well applicable.
Fig. 13 Results for data set \#13 (FAT 70, $m=3.0,1: \mathrm{T}_{\mathrm{S}}=1.24$ )

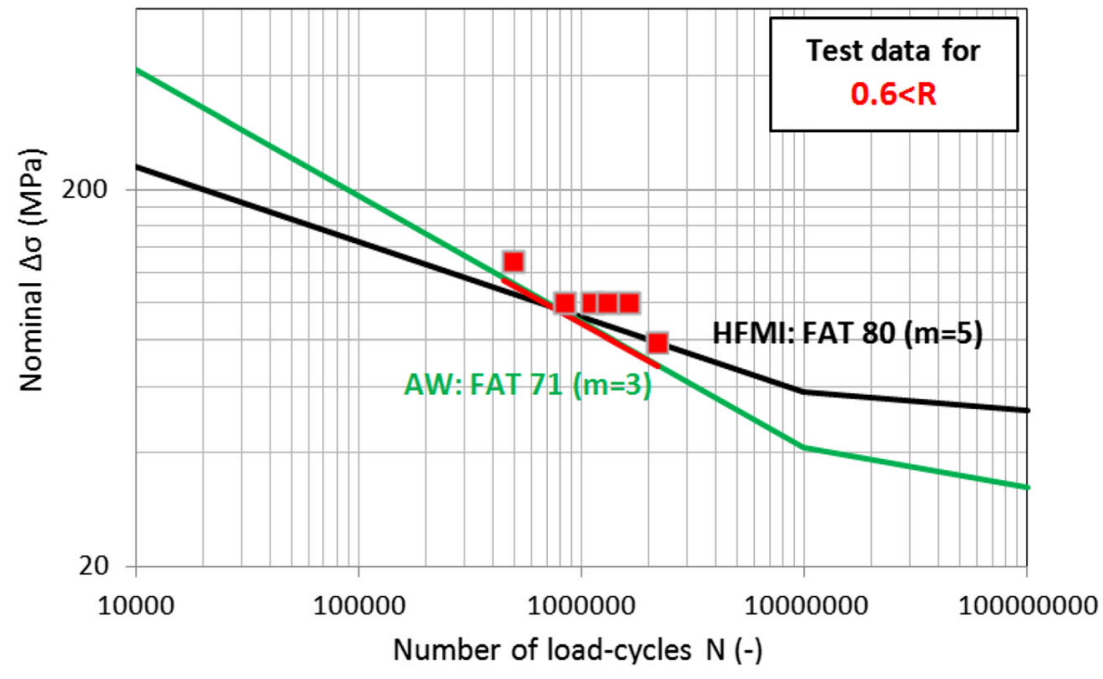


Fig. 14 Results for data set \#14 (FAT $160, m=5.6,1: \mathrm{T}_{\mathrm{S}}=1.37$ )

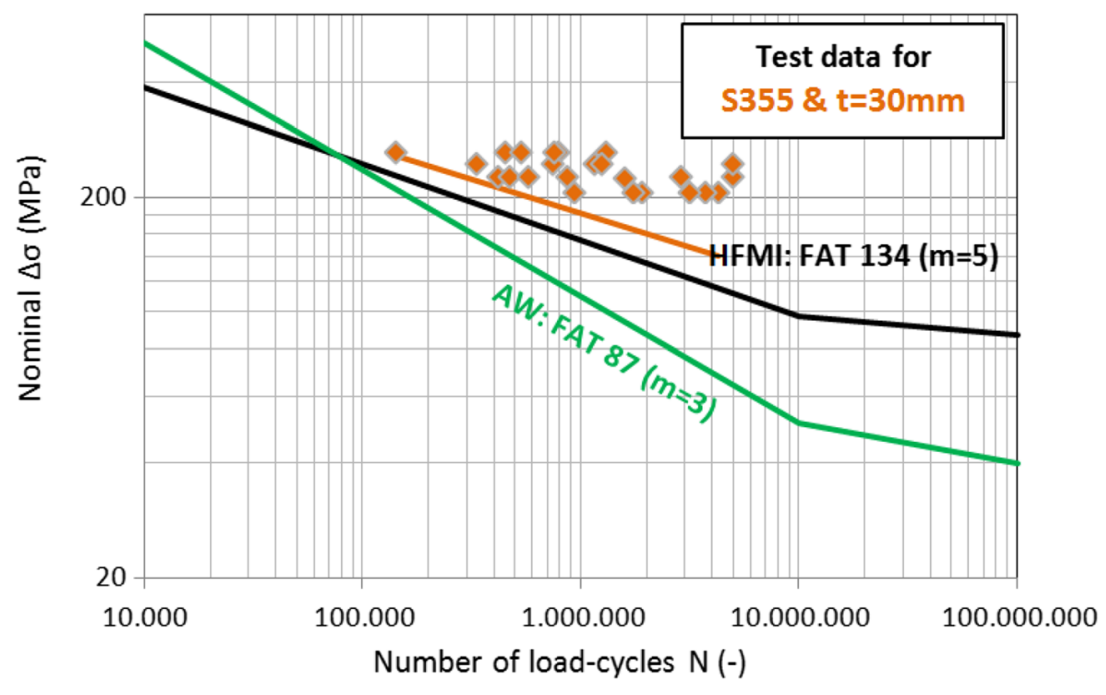

\subsection{Effect of increased plate thickness}

At third, the effect of increased base plate thicknesses on the fatigue strength of HFMI-treated steel joints is investigated. The thickness correction factor $f(t)$ is considered as presented by Eq. (1). In case of the HFMI-treated condition, an exponent of 0.2 is applied as shown, for the AW condition, an exponent of 0.3 for T-joints and longitudinal stiffeners and an exponent of 0.2 for butt joints as recommended within the IIWguideline for welded structures [1]. In Fig. 14, the results for data set \#14 are depicted. The results include a S355 butt joint specimen with a plate thickness of $t=30 \mathrm{~mm}$ tested under tensile loading at a load stress ratio of $\mathrm{R}=0.1$. The AW fatigue class without considering the thickness effect is defined as FAT 90. The thickness factor is calculated to $f(t)=0.96$ utilizing an exponent of 0.2 for butt joints, which leads to a reduced fatigue class of FAT 87 independent of the yield strength of the base material. The HFMI-treated fatigue class is defined as FAT 140 without thickness correction. The thickness correction factor is computed to the same value of $f(t)=0.96$ as the same exponent is usable. Hence, a fatigue class of FAT 134 is defined for the HFMI-treated condition utilizing this specimen geometry with a mild steel S355 as base material.

A comparison of the fatigue test data points and their statistically evaluated $\mathrm{S} / \mathrm{N}$ curve with the recommended $\mathrm{S} / \mathrm{N}$ curve highlights that the HFMI guideline considering the thickness effect is well applicable and leads to a conservative assessment.

Figure 15 depicts the results for data set \#15, which includes the same specimen geometry and load stress ratio as data set \#14, but a different base material yield strength of $460 \mathrm{MPa}$. Thereby, the fatigue class for the AW condition as FAT 87 as same as before. In case of the HFMI-treated state, a fatigue class of FAT 154 is applicable considering the higher base material strength and the thickness correction factor. Again, a comparison of the recommended $\mathrm{S} / \mathrm{N}$ curve with the test data points and their statistically evaluated $\mathrm{S} / \mathrm{N}$ curve reveals a sound practicability of the HFMI guideline.
Fig. 15 Results for data set \#15 (FAT $202, m=7.4,1: \mathrm{T}_{\mathrm{S}}=1.12$ )

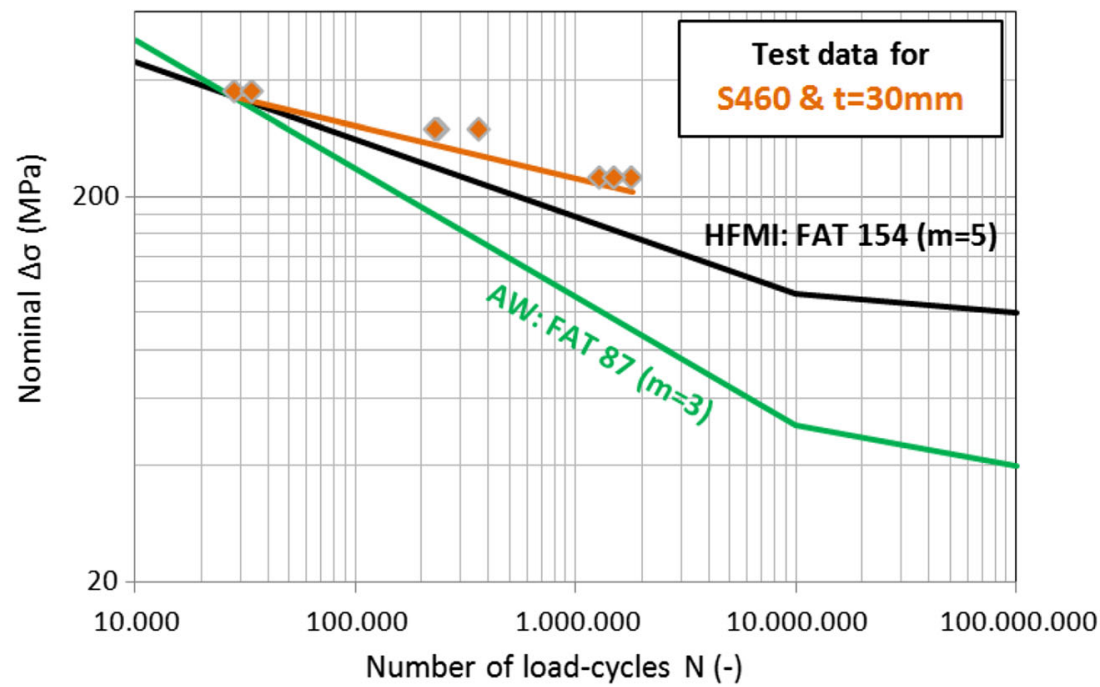


Fig. 16 Results for data set \#16 (FAT $210, m=6.6,1: \mathrm{T}_{\mathrm{S}}=1.22$ )

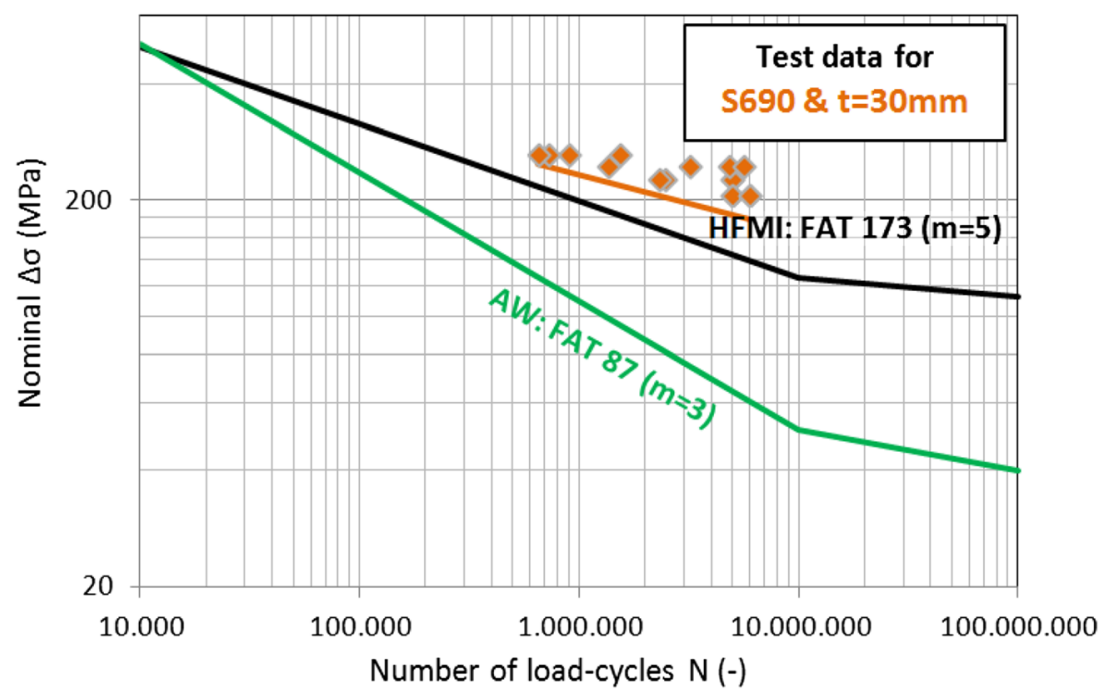

The same specimen geometry and testing conditions are utilized in data set \#16, see Fig. 16, but herein, a highstrength steel S690 is used as base material. The fatigue class of the AW condition keeps constant with FAT 87, but for the HFMI-treated state, a higher value of FAT 173 considering the increased yield strength and the thickness correction factor is applicable. The results maintain once more that all test data points as well as their statistically evaluated $\mathrm{S} / \mathrm{N}$ curve lay above the recommended assessment line.

In Fig. 17, the results for the data set \#17 are illustrated. On the contrary to the preceding analyses, a longitudinal stiffener with a plate thickness of $t=30 \mathrm{~mm}$ is utilized in this case. For this structural detail, the AW condition is defined as FAT 63 without thickness correction. Considering a thickness correction factor of $f(t)=0.95$ calculated an exponent of 0.3 , a fatigue class of FAT 60 is applicable. For the HFMI-treated state, FAT 100 without and FAT 96 with consideration of a thickness correction of $f(t)=0.96$ computed with an exponent of 0.2 is recommended. The results again proof a conservative fatigue assessment of the fatigue test data points and their statistically evaluated $\mathrm{S} / \mathrm{N}$ curve based on the HFMI guideline considering the thickness effect.

The same longitudinal stiffener with the same testing conditions, but exhibiting an increased yield strength of $690 \mathrm{MPa}$, is investigated in data set \#18, see Fig. 18. The AW condition keeps unchanged with a fatigue class of FAT 60 , and the HFMI-treated condition is evaluated as FAT 120 considering the increased base material strength and the thickness correction. A comparison highlights that also for this high-strength steel, the recommended $\mathrm{S} / \mathrm{N}$ curve by the HFMI guideline is well applicable to the fatigue test data points and their statistically evaluated $\mathrm{S} / \mathrm{N}$ curve.

As third part of this test series, a S460 T-joint with the same testing conditions as shown in the preceding investigations is included within data set \#19, see Fig. 19. The AW fatigue class is defined as FAT 80 without thickness correction. Applying a factor of $f(t)=0.95$ calculated with an exponent of 0.3 , this fatigue class reduces to FAT 76 in this case. For the
Fig. 17 Results for data set \#17

(FAT $138, m=5.6,1: \mathrm{T}_{\mathrm{S}}=1.34$ )

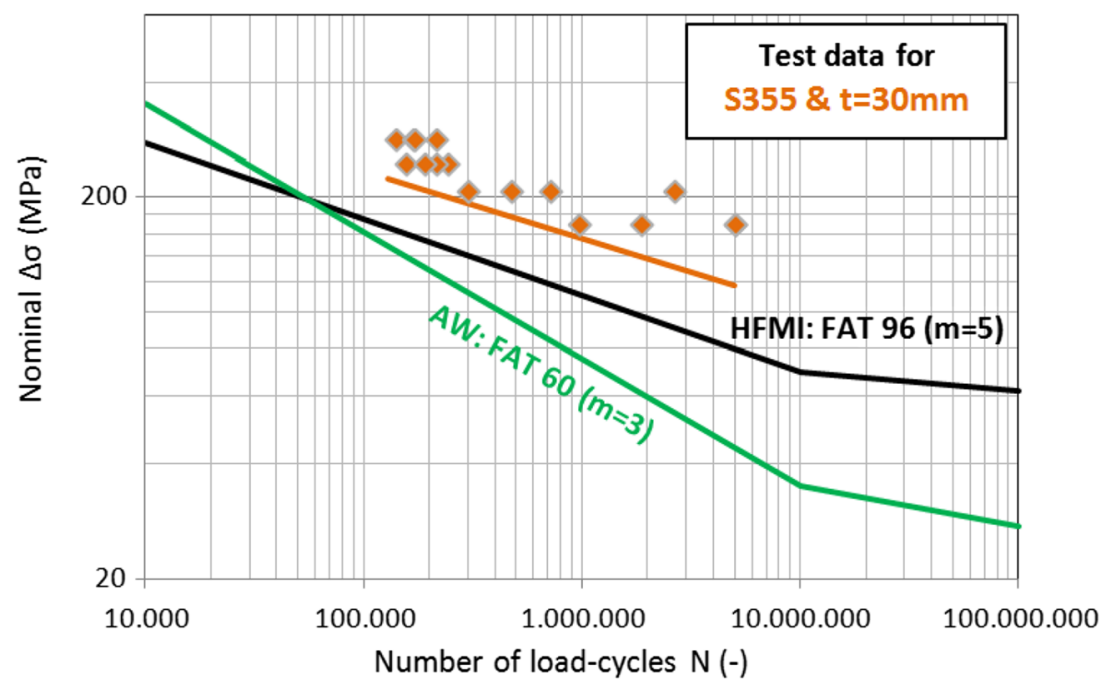


Fig. 18 Results for data set \#18 (FAT 161, $m=4.2,1: \mathrm{T}_{\mathrm{S}}=1.07$ )

Fig. 19 Results for data set \#19 (FAT $180, m=6.3,1: \mathrm{T}_{\mathrm{S}}=1.08$ )

Fig. 20 Results for data set \#20 (FAT $186, m=6.5,1: \mathrm{T}_{\mathrm{S}}=1.31$ )
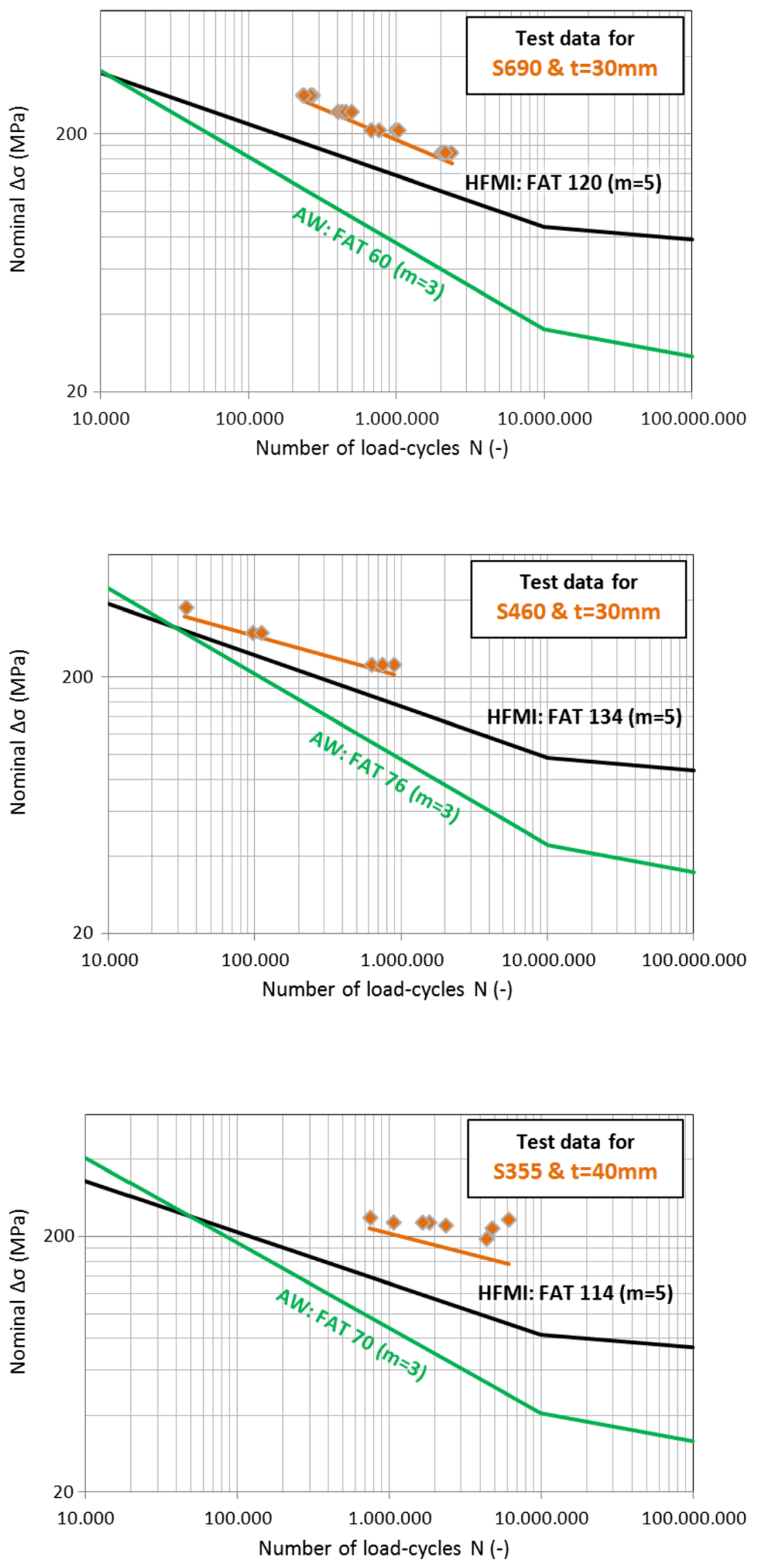
Fig. 21 Results for data set \#21

(FAT 189, $m=12.0,1: \mathrm{T}_{\mathrm{S}}=1.10$ )

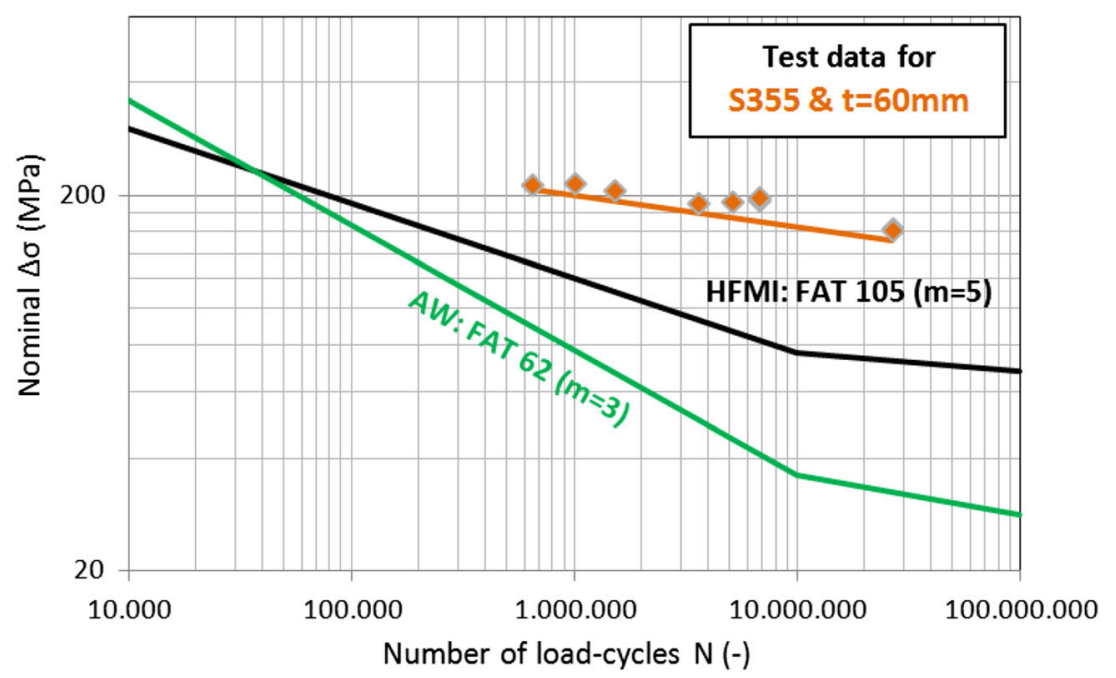

HFMI-treated condition, a value of FAT 140 is recommended without thickness correction. Considering a thickness correction factor of $f(t)=0.96$, this values is reduced to FAT 134, which is shown in the evaluation. A comparison of the recommended fatigue behavior with the fatigue test data points and their statistically evaluated $\mathrm{S} / \mathrm{N}$ curve highlights a sound applicability facilitating a conservative assessment.

Different to all presented test data before, the following data sets include experiments, which are tested under bending load. The IIW-guideline does not explicitly distinguish between tensile and bending load in regard to the fatigue resistance; however, as both are defined as normal stresses, the same fatigue classes without any bending correction factor are applied and utilized within this analysis.

In Fig. 20, the results for data set \#20 are presented. Thereby, the fatigue test data of a S355 T-joint specimen tested under four-point-bending loading at a load stress ratio of about $\mathrm{R}=0.1$ is included. The fatigue class of the AW condition is defined as FAT 80 without thickness correction. In order to properly compare this fatigue bending test data with the recommended $\mathrm{S} / \mathrm{N}$ curve, which is generally applicable for membrane stress, an approach given in the British Standard BS 7608:2014 [27] is utilized. Thereby, the effect of sheet thickness combined with the influence of bending is considered by a correction factor $k_{t b}$, see Eq. (2). The thickness exponent for peened weld toes is defined as $b=0.25$, which is different to the value of 0.2 within the IIW-guideline. The second term of this equation, represented as $\left[1+0.18 \Omega^{1.4}\right]$, describes the influence of bending with parameter $\Omega$ denoted as degree of bending, which is evaluated on the basis of the bending stress range $\Delta \sigma_{b}$ and the membrane stress range $\Delta \sigma_{m}$, see Eq. (3).

$k_{t b}=\left(\frac{25}{t_{e f f}}\right)^{b} \cdot\left[1+0.18 \cdot \Omega^{1.4}\right]$

with $\Omega=\Delta \sigma_{b} /\left(\Delta \sigma_{m}+\Delta \sigma_{b}\right)$

In case of pure bending, the degree of bending equals a value of $\Omega=1$, which is used in this case. As the thickness
Fig. 22 Results for data set \#22 (FAT $186, m=7.6,1: \mathrm{T}_{\mathrm{S}}=1.43$ )

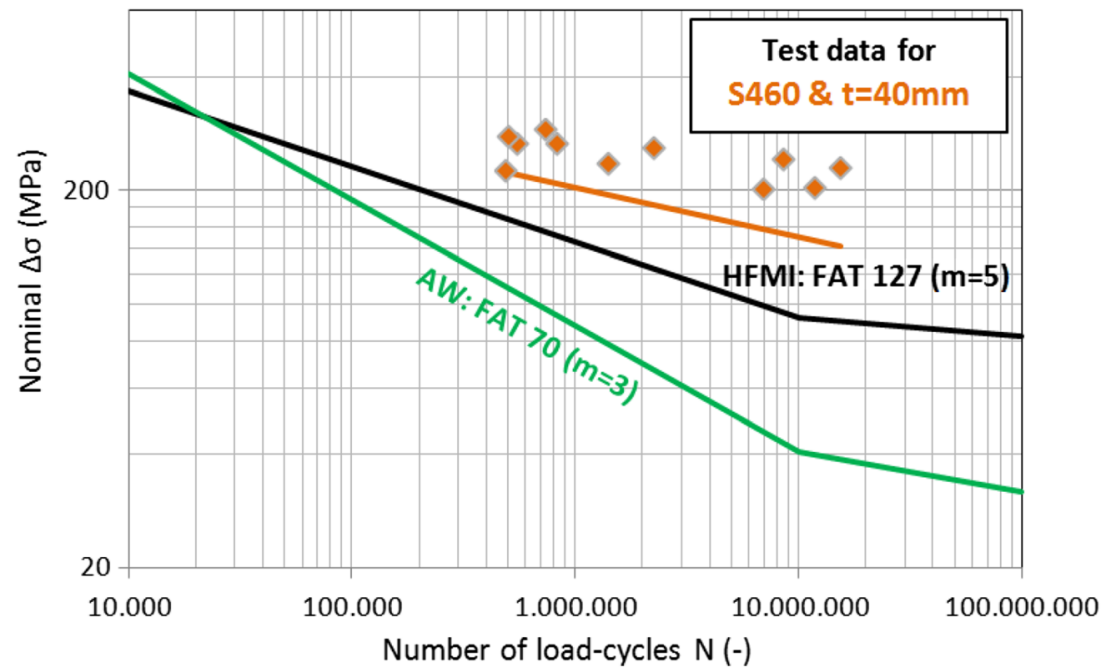


Fig. 23 Results for data set \#23

(FAT 206, $m=11.6,1: \mathrm{T}_{\mathrm{S}}=1.29$ )

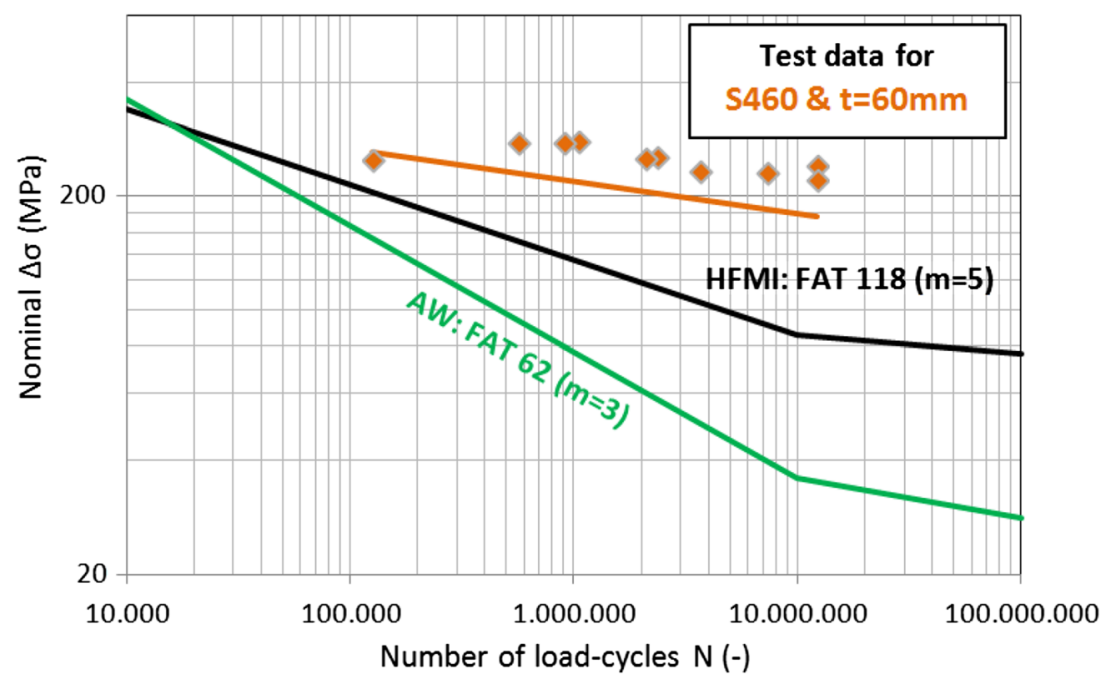

effect is already included within the IIW-recommended AW and HFMI-curves, only the second term considering the effect of bending, which resulted in a calculated factor of $k_{t b}=[1+$ $\left.0.181^{1.4}\right]=1.18$, is reductively applied on the bending fatigue test data in order to ensure a sound comparability between the test data and the recommended $\mathrm{S} / \mathrm{N}$ curves. Considering the IIW-thickness correction factor of $f(t)=0.87$ using a thickness exponent of 0.3 , the AW fatigue class is reduced to FAT 70. In case of the HFMI-treated state, the FAT value is defined as FAT 125 without thickness correction. Applying a thickness
Table 3 Summary of results for HFMI-treated condition

\begin{tabular}{|c|c|c|c|c|c|c|}
\hline Data set & Reference & $\begin{array}{l}\text { FAT class of } \\
\text { test data }[\mathrm{MPa}]\end{array}$ & Slope $m[-]$ & $\begin{array}{l}\text { Scatter band } \\
1: T_{\mathrm{S}}[-]\end{array}$ & $\begin{array}{l}\text { FAT class based } \\
\text { on }[15][\mathrm{MPa}]\end{array}$ & $\begin{array}{l}\text { Ratio of } \\
\text { FAT class }\end{array}$ \\
\hline$\# 1$ & [19] & 309 & 5.1 & 1.14 & 180 & 1.72 \\
\hline$\# 2$ & {$[20]$} & 170 & 3.6 & 1.53 & 180 & $0.94 *$ \\
\hline$\# 3$ & {$[21]$} & 215 & 6.5 & 1.23 & 140 & 1.54 \\
\hline$\# 4$ & {$[21]$} & 204 & 5.4 & 1.03 & 140 & 1.46 \\
\hline$\# 5$ & [21] & 148 & 3.0 & 1.17 & 180 & $0.82 *$ \\
\hline \#6 & [21] & 180 & 5.0 & 1.18 & 180 & 1.00 \\
\hline \#7 & [21] & 163 & 4.9 & 1.21 & 140 & 1.16 \\
\hline$\# 8$ & [21] & 84 & 3.0 & 1.11 & 140 & $0.60 *$ \\
\hline \#9 & [22] & 169 & 6.8 & 1.14 & 125 & 1.35 \\
\hline$\# 10$ & {$[22]$} & 122 & 5.7 & 1.18 & 112 & 1.09 \\
\hline \#11 & {$[22]$} & 108 & 5.4 & 1.15 & 100 & 1.08 \\
\hline$\# 12$ & {$[22]$} & 92 & 5.1 & 1.34 & 90 & 1.02 \\
\hline$\# 13$ & {$[22]$} & 70 & 3.0 & 1.24 & 80 & $0.88^{*}$ \\
\hline$\# 14$ & [23] & 160 & 5.6 & 1.37 & 134 & 1.19 \\
\hline$\# 15$ & {$[23]$} & 202 & 7.4 & 1.12 & 154 & 1.31 \\
\hline$\# 16$ & [23] & 210 & 6.6 & 1.22 & 173 & 1.21 \\
\hline$\# 17$ & [23] & 138 & 5.6 & 1.34 & 96 & 1.44 \\
\hline$\# 18$ & [23] & 161 & 4.2 & 1.07 & 120 & 1.34 \\
\hline \#19 & {$[23]$} & 180 & 6.3 & 1.08 & 134 & 1.34 \\
\hline$\# 20$ & {$[24]$} & 186 & 6.5 & 1.31 & 114 & 1.63 \\
\hline$\# 21$ & [24] & 189 & 12.0 & 1.10 & 105 & 1.80 \\
\hline$\# 22$ & [24] & 186 & 7.6 & 1.43 & 127 & 1.46 \\
\hline$\# 23$ & [24] & 206 & 11.6 & 1.29 & 118 & 1.75 \\
\hline
\end{tabular}

*Although the statistically evaluated FAT class is below the recommended value, all investigated fatigue test data points are assessed conservatively based on [15], see results in Sects. 2.2 and 2.3 
correction factor of $f(t)=0.91$ with an exponent of 0.2 , the fatigue class is calculated to FAT 114, which is finally used for the fatigue assessment. Although the bending effect is considered for the fatigue test data, a comparison of the test data points and their statistically evaluated $\mathrm{S} / \mathrm{N}$ curve with the assessment line reveals that the HFMI guideline leads to an increased conservative assessment by considering the IIW-recommended thickness correction factor.

Figure 21 depicts the results for data set \#21, at which the same specimen geometry and base material as for data set \#20, but with an further increased plate thickness of $t=60 \mathrm{~mm}$, is utilized. The thickness correction for the AW condition is calculated to $f(t)=0.77$ and for the HFMI-treated state to $f(t)=0.84$ leading to FAT 62 and FAT 105 , respectively. Again, the fatigue tests data points and their statistically evaluated $\mathrm{S} / \mathrm{N}$ curve are assessed conservatively, although the bending effect is considered based on the previously described approach.

In Figs. 22 and 23, the results for data set \#22 and \#23 are shown. The same specimen geometry and bending test conditions as shown in the previous test series are included. On the contrary, an increased yield base material strength of $460 \mathrm{MPa}$ is used in this case. For the AW condition, the same FAT values and thickness correction factors apply. For the HFMItreated condition, fatigue classes of FAT 127 for $t=40 \mathrm{~mm}$ and FAT 118 for $t=60 \mathrm{~mm}$ considering the same thickness correction factors as shown before are evaluated. The bending effect is again taken into account by reducing the bending fatigue test data points by a calculated bending factor of $k_{\mathrm{tb}}=$ 1.18. The results reveal that the data points and statistically evaluated $\mathrm{S} / \mathrm{N}$ curves for both test cases are conservatively assessed applying the recommended thickness factor.

Summarizing the results of this section, the recommended $\mathrm{S} / \mathrm{N}$ curves considering the thickness correction factor lead again to a conservative fatigue assessment based on the investigated test data and statistically evaluated $\mathrm{S} / \mathrm{N}$ curves. None of the test results and evaluated $\mathrm{S} / \mathrm{N}$ curves is located below the recommended assessment lines, which validates the applicability of the HFMI guideline as well as the use of the thickness correction factor $f(t)$.

\subsection{Summary}

In Table 3, a summary of the results as investigated in Sects. 2.2 to 2.4 is shown. Thereby, the statistically evaluated FAT class, slope $m$, and scatter band $1: \mathrm{T}_{\mathrm{S}}$ of the test data are given. In addition, the recommended FAT class for the HFMI-treated condition based on [15] is presented. Finally, the ratio of the statistically evaluated FAT class by the test data to the recommended value is shown. It can be observed that, except for the test data sets \#2, \#5, \#8, and \#13, the ratio of the FAT class is above one resulting in a conservative fatigue assessment applying the recommendation. It has to be stated that for these four data sets, whereat the ratio of the FAT class is below one, only the statistically evaluated FAT class of the test data is below the recommended value, but every single fatigue test data point is still assessed conservatively. To sum up, this comprehensive validation of the HFMI recommendation [15], covering fatigue test data sets with increased base material yield strengths, R-ratios, and plate thicknesses, reveals a conservative assessment of every investigated test data point.

\section{Conclusions}

This paper compares fatigue test data, involving results for HFMI-treated steel joints from 23 published data sets, with the recommended values by the IIW recommendation for the HFMI treatment [15]. The analysis reveals that the recommended improvement of fatigue classes based on the base material yield strength is well applicable. In addition, the reduction of fatigue classes for higher R-ratios up to the defined value of $R=0.52$ is well considered within the guideline. Finally, the practicability of the thickness correction factor is also confirmed by leading to a conservative fatigue assessment. The ratio of the statistically evaluated FAT class to the recommended value is shown to be conservative with a value of above one for almost every data set; however, even the ratio is below one in some minor cases, every single test data point in this study is assessed conservatively validating the applicability of the recommendation. Further focus should be laid on the effect of variable amplitude loading, as shown in [28-30], in order to validate the practicality of suggested damage sum values for a conservative fatigue design under in-service load conditions.

Acknowledgements Open access funding provided by Montanuniversität Leoben.

Open Access This article is licensed under a Creative Commons Attribution 4.0 International License, which permits use, sharing, adaptation, distribution and reproduction in any medium or format, as long as you give appropriate credit to the original author(s) and the source, provide a link to the Creative Commons licence, and indicate if changes were made. The images or other third party material in this article are included in the article's Creative Commons licence, unless indicated otherwise in a credit line to the material. If material is not included in the article's Creative Commons licence and your intended use is not permitted by statutory regulation or exceeds the permitted use, you will need to obtain permission directly from the copyright holder. To view a copy of this licence, visit http://creativecommons.org/licenses/by/4.0/.

\section{References}

1. Hobbacher A (2009) IIW recommendations for fatigue design of welded joints and components. WRC, New York 
2. Haagensen PJ, Maddox SJ (2013) IIW recommendations on methods for improving the fatigue strength of welded joints, IIW2142-10, Woodhead Publishing

3. Hansen AV, Agerskov H, Bjørnbak-Hansen J (2007) Improvement of fatigue life of welded structural components by grinding. Welding in the World 51:61-67

4. Yildirim H (2015) Review of fatigue data for welds improved by tungsten inert gas dressing. Int J Fatigue 79:36-45

5. Tai M, Miki C (2014) Fatigue strength improvement by hammer peening treatment - verification from plastic deformation, residual stress, and fatigue crack propagation rate. Welding in the World 58: 307-318

6. Fueki R, Takahashi K, Handa M (2019) Fatigue limit improvement and rendering defects harmless by needle peening for high tensile steel welded joint. Metals 9:143

7. Weich I, Ummenhofer T, Nitschke-Pagel T, Dilger K, Eslami H (2009) Fatigue behaviour of welded high-strength steels after high frequency mechanical post-weld treatments. Welding in the World 53:322-332

8. Weich I, Ummenhofer T (2011) Effects of high-frequency peening methods on the surface layers and the fatigue strength of welded details. Mater Manuf Process 26:288-293

9. Kuhlmann U, Bergmann J, Dürr A, Thumser R, Günther H-P, Gerth $U$ (2005) Enhancement of the fatigue strength of welded high strength steels by application of post-weld treatment methods. Stahlbau 74:358-365 (in German)

10. Khurshid M, Leitner M, Barsoum Z, Schneider C (2017) Residual stress state induced by high frequency mechanical impact treatment in different steel grades - numerical and experimental study. Int J Mech Sci 123:34-42

11. Leitner M, Khurshid M, Barsoum Z (2017) Stability of high frequency mechanical impact (HFMI) post-treatment induced residual stress states under cyclic loading of welded steel joints. Eng Struct 143:589-602

12. Khurshid M, Barsoum Z, Marquis G (2014) Behavior of compressive residual stresses in high strength steel welds induced by high frequency mechanical impact treatment. ASME Journal of Pressure Vessel Technology 136:1-8

13. Yildirim H, Leitner M, Marquis G, Stoschka M, Barsoum Z (2016) Application studies for the fatigue strength assessment of welded structures improved by HFMI. Journal of Engineering Structures 106:422-435

14. Leitner M, Barsoum Z, Schäfers F (2016) Crack propagation analysis and rehabilitation by HFMI of pre-fatigued welded structures. Welding in the World 60:581-592

15. Marquis GB, Barsoum Z (2016) IIW recommendations for the HFMI treatment - for improving the fatigue strength of welded joints, ISBN 978-981-10-2503-7, Springer
16. Yildirim HC, Marquis GB (2012) Overview of fatigue data for high frequency mechanical impact treated welded joints. Welding in the World 56:82-96

17. Mikkola E, Doré M, Khurshid M (2013) Fatigue strength of HFMI treated structures under high R-ratio and variable amplitude loading. Procedia Engineering 66:161-170

18. Yildirim HC, Marquis G (2015) Fatigue data of high-frequency mechanical impact (HFMI) improved welded joints subjected to overloads. Analysis and Design of Marine Structures:317-322

19. Ottersböck M, Leitner M, Stoschka M, Maurer W (2019) Crack initiation and propagation fatigue life of ultra high-strength steel butt joints. Appl Sci 9:4590

20. Nykänen T, Björk T, Laitinen R (2012) Fatigue strength prediction of ultra high strength steel butt-welded joints. Fatigue Fract Engng Mater Struct 36:469-482

21. Berg J, Stranghoener N (2014) Fatigue strength of welded ultra high strength steels improved by high frequency hammer peening. Procedia Mater Sci 3:71-76

22. Yonezawa T, Shimanuki H, Mori T (2020) Influence of cyclic loading on the relaxation behavior of compressive residual stress induced by UIT. Welding in the World 64:171-178

23. Ummenhofer T, Weidner P (2013) Improvement factors for the design of welded joints subjected to high frequency mechanical impact treatment. Steel Construction 6(3):191-199

24. Shams-Hakimi P, Zamiri F, Al-Emrani M, Barsoum Z (2018) Experimental study of transverse attachment joints with 40 and $60 \mathrm{~mm}$ thick main plates, improved by high-frequency mechanical impact treatment (HFMI). Eng Struct 155:251-266

25. ASTM International (1998) Standard practice for statistical analysis of linear or linearized stress-life (S-N) and strain-life $(\varepsilon-\mathrm{N})$ fatigue data, designation: E739-91, reapproved

26. Haibach E (2006) Betriebsfestigkeit, Springer Verlag. (in German)

27. British Standard BS (2014) 7608:2014: Guide to fatigue design and assessment of steel products, British Standards Institution

28. Leitner M, Ottersböck M, Pußwald S, Remes H (2018) Fatigue strength of welded and high frequency mechanical impact (HFMI) post-treated steel joints under constant and variable amplitude loading. Eng Struct 163:215-223

29. Yildirim HC, Marquis G, Sonsino CM (2016) Lightweight design with welded high-frequency mechanical impact (HFMI) treated high-strength steel joints from S700 under constant and variable amplitude loadings. Int J Fatigue 91:466-474

30. Berg J, Stranghöner N, Kern A, Hövel M (2016) Variable amplitude fatigue tests at high frequency hammer peened welded ultra high strength steel S1100. Procedia Structural Integrity 2:3554-3561

Publisher's note Springer Nature remains neutral with regard to jurisdictional claims in published maps and institutional affiliations. 